\title{
Clinical Impact of the Patient Age Following Endoscopic Third Ventriculostomy: A Review
}

\section{Dipak Chaulagain ${ }^{1}$, Volodymyr Smolanka ${ }^{2}$, Andriy Smolanka ${ }^{3}$, Taras Havryliv ${ }^{4}$, Volodymyr Smolanka Jr${ }^{5}$, Sunil Munakomi ${ }^{6}$}

${ }^{1} \mathrm{PhD}$ Candidate in Neurosurgery, University: Uzhhorod National University, Uzhhorod, Ukraine ${ }^{2}$ Professor, Uzhhorod National University, Uzhhorod, Ukraine

${ }^{3}$ Associate Professor- Neurosurgery, University: Uzhhorod National University, Uzhhorod, Ukraine ${ }^{4}$ Assistant Professor- Neurosurgery, University: Uzhhorod National University, Uzhhorod, Ukraine ${ }^{5}$ Assistant Professor- Neurosurgery, University: Uzhhorod National University, Uzhhorod, Ukraine ${ }^{6}$ Associate Professor- Neurosurgery, University: College of Medical Sciences, Bharatpur, Nepal

Corresponding Author: Dipak Chaulagain

\begin{abstract}
Background: Clinically erratic cerebrospinal fluid (CSF) outflow within brain ventricles was described as non-communicating and communicating hydrocephalous. Neurosurgical patients are commonly seen with increased intracranial pressure due to increased CSF accumulation. (1) Initially scientists followed ventriculoperitoneal shunt an inexpensive and available technique to treat hydrocephalous disorders. Due to least successful outcomes, Scientists used other alternative endoscopic techniques. These endoscopic techniques include aqueductal endoscopic stenting, aqueductoplasty and third ventriculostomy (2). Defining success rate of Endoscopic third ventriculostomy clinical and radiographic analysis are considered gold standard.
\end{abstract}

Objectives: Our review aims to assess comparative role of patient age, patient selection, hydrocephalus etiology, surgical advancement and epigenetic treatment strategies following endoscopic third ventriculostomy focusing hydrocephalous. The main objectives of current study, to critically analyze available literature till to date and a step forward for the development of standard surgical protocols.

Methodology: Clinical studies from Level I-IV published in English language focusing human subject only were only considered by retrieving NCBI/PubMed, Medline databases. Studies purely focusing third ventriculostomy in subject of patient age, hydrocephalus etiology and age associated complications were processed further. Objective based data inspection approach was followed. From each included study focusing third ventriculostomy detailed information demographic information was collected. Further data analysis was done by using SAS and multiple tools of Microsoft Excel Version 2010.

Outcomes: From total 11 included studies specifically focusing hydrocephaly treatment via endoscopic third ventriculostomy, 757 patients with equal 1:1 male and female gender ratio and 125 cases of unknown gender were considered. Current study highlighting efficacy of Endoscopic third ventriculostomy at the rate of $77 \%$ effective treating obstructive hydrocephalus. On basis of etiological concerns about $36.32 \%$ cases hydrocephalous cases were linked with encephalitis, underweight birth and nonspecific etiology. However, $24 \%$ cases of hydrocephalus were led by group of tumors including, Ependymoma, Medulloblastoma, Meningioma, Cerebella pontine angle Tumors and Pineal gland carcinomas as well. 154 (20\%) cases of obstructive hydrocephalus were associated with aqueduct stenosis, $16 \%$ cases reporting hemorrhage and only 23 cyst cases.

Conclusion and future recommendations: Endoscopic third ventriculostomy (ETV) is a safe and effective (77\%) treatment option for the treatment of obstructive hydrocephalus among all age groups. However, specifically highest efficacy was noted among patients of 15-30-year age group. Understanding disease etiology and patient selection criteria both are considered potential components 
Dipak Chaulagain et.al. Comparative role of hydrocephalus etiology and patient age following third ventriculostomy.

following successful endoscopic third ventriculostomy. We highly recommend further research following a universal age criteria and reporting results in distinct age category to standardize ETV treating hydrocephaly efficiently.

Keywords: Endoscopic third ventriculostomy, ETV, hydrocephalous, aqueductal endoscopic stenting, aqueductoplasty.

\section{INTRODUCTION}

Classically erratic cerebrospinal fluid (CSF) outflow within brain ventricles was described as non-communicating and communicating hydrocephalous. Neurosurgical patients are commonly seen with increased intracranial pressure due to increased CSF accumulation. (1)Initially scientists followed ventriculoperitoneal shunt an inexpensive and available technique to treat hydrocephalous disorders. Due to least successful outcomes, Scientists used other alternative endoscopic techniques. These endoscopic techniques include aqueductal endoscopic stenting, aqueductoplasty and third ventriculostomy (2). Defining success rate of Endoscopic third ventriculostomy clinical and radiographic analysis are considered gold standard. Clinically patients suffering from obstructive hydrocephalous feel relieves from headache, tension and improvements in ocular movement. Radiographic improvements include significant reduction in size of third ventricle at the rate of $15 \%$ per month (3-5). Managing obstructive hydrocephalus by third ventriculostomy in selected patients is safer and effective treatment option in comparison to ventriculoperitoneal shunt surgery (VPS). Repeated ventriculoperitoneal shunt surgery causes infection in some patients and reported death rate are very high (6-9). However, endoscopic third ventriculostomy has some potential complications (10). Certain magnetic resonance imaging (MRI) based indications are followed before operating third ventriculostomy (11). It's still unclear to ideal patient age following endoscopic third ventriculostomy (12). The aim following third ventriculostomy is to manage obstructive hydrocephalus by diversion of abnormal intracranial cerebrospinal fluid with least possible complications (13-14).

\subsection{Endoscopic Anatomy}

Understanding third ventricle anatomy and neighboring tissue structure is considered very useful to overcome endoscopic third ventriculostomy associated complications. According to study conducted by Yadav YR et al., 2012highlighted the significant impact of third ventriculostomy on ependymal, stroma cells and arachnoid membrane among enlarged ventricle patients. Author recommend apex of the mamillary bodies an ideal site for third ventriculostomy without effecting neighbor cells to third ventricle (1)

\subsection{Indications}

Many neurosurgeons recognize endoscopic third ventriculostomy a reliable treatment option for obstructive hydrocephalus among adult patients with an average of $88 \%$ success rate(15). Similarly, another study supported Endoscopic third ventriculostomy role in clinical improvements among $88.6 \%$ patients(16). Identification of previous third ventriculostomy is significant in-patient selection as repeated third ventriculostomy lowers the chances of successful treatment of obstructive hydrocephalus $(16,17)$. In case of aqueduct of Sylvius obstruction and tumors third ventriculostomy seems best treatment option (18-20). However, endoscopic third ventriculostomy among children's less than six months of age is least successful treatment option $(21,22)$.

\subsection{Surgical interventions}

Surgical interventions following third ventriculostomy include creation of burr hole in dura and by using blunt cannula cerebrospinal fluid outflow was managed. 
Dipak Chaulagain et.al. Comparative role of hydrocephalus etiology and patient age following third ventriculostomy.

The whole surgical process was regulated by using lotta endoscope an optical visualization unit by following standard disinfection and anesthesia protocols (23). Clear visualization of CSF outflow requires Liliequist's membrane puncture without effecting mamillary bodies and neighboring arterioles. Similarly, for the visualization of third ventricle, opening third ventricle floor by ballooning demands meticulous care and prior fornix visualization (22).

\subsection{Treatment modalities and clinical conditions}

Endoscopic third ventriculostomy surgery is considered best available treatment option overcoming obstructive hydrocephalous. However, ETV success rate depends upon set of two variables including physiological and histological variables. Physiological variables include patient age, history of previous surgery and etiology of obstructive hydrocephalus. Whereas histological variables include storma mobility, bleeding, adhesion molecules presence and the most important one Liliequist's membrane puncture (2325).

Clinical outcomes following third ventriculostomy include significant decrease in ventricular size in hydrocephalus patients relevant to patient selection. Similarly, other important intraoperative treatment factors following third ventriculostomy include duration of surgical procedure and bleeding time $(25,26)$.

\subsection{Age Associated Complications}

In comparison to shunt ventriculostomy endoscopic third ventriculostomy surgical technique prevents from potential risk of vascular injury. ETV success rate after shunt ventriculostomic surgery is still unclear (22). Extending author report regarding significant positive impact of third ventriculostomy among children and infants as per increase in their age. Many authors contradict this hypothesis and consider etiology of hydrocephalous more important rather than age of children's following third ventriculostomy $(27,28)$.

Our review aims to assess comparative role of patient age, patient selection, hydrocephalus etiology, surgical advancement and epigenetic treatment strategies following endoscopic third ventriculostomy focusing hydrocephalous. The main objectives of current study, to critically analyze available literature till to date and a step forward for the development of standard surgical protocols.

\section{METHODOLOGY}

\subsection{Eligibility criteria:}

Clinical studies published in English language focusing human subject only were only considered by retrieving NCBI/PubMed, Medline databases. Approximately, 2939 related articles were found. By applying filtering approach 158clinical full text free articles were found from recent five year. Clinical studies including clinical trials level-III and LevelIV were only considered. Whereas, 59 articles were focusing ventricular shunt osteotomy and related surgical techniques. Specifically, only 11 studies focusing third ventriculostomy met inclusion criteria. Studies purely focusing third ventriculostomy in subject of patient age, hydrocephalus etiology and age associated complications were included (Table.1).

Table.1. Studies inclusion and exclusion criteria.

\begin{tabular}{|l|l|l|}
\hline Obs & Inclusion Criteria & Exclusion criteria \\
\hline 1 & Studies followed ETV surgical technique & Studies followed other than ETV surgical procedure \\
\hline 2 & Evidence level I, II III, IV & $\begin{array}{l}\text { Review articles, case reports, letter to the editor and short } \\
\text { communication }\end{array}$ \\
\hline 5 & Articles written in English language & Studies published in Other than English language \\
\hline 5 & $\begin{array}{l}\text { Studies reported not older then 1st January, } \\
2015\end{array}$ & Studies published before 31 December 2014. \\
\hline 6 & Patients from irrespective of age and gender & Studies reporting no relevant age and gender associated information. \\
\hline
\end{tabular}


Dipak Chaulagain et.al. Comparative role of hydrocephalus etiology and patient age following third ventriculostomy.

\subsection{Search strategies:}

All included studies were carefully searched from NCBI/PubMed and Medline databases. All shortlisted studies were only from Scopus indexed journals. Search strategy was made by using key words, endoscopic third ventriculostomy, endoscopic anatomy, endoscopic ventriculostomy challenges, hydrocephalus etiology, age impact on third ventriculostomy, third ventriculostomy complications, ideal patient selection for surgery and ETV treatment modalities. One author cross checked the searched articles either article is surely indexed.

Table.2. Article Search strategies from different databases.

\begin{tabular}{|c|c|c|c|c|c|c|c|}
\hline No. & Search Terms & & & $\begin{array}{l}\text { Different Database } \\
\text { Search Results }\end{array}$ & & & $\begin{array}{l}\text { Overall } \\
\text { Results }\end{array}$ \\
\hline & & PubMed & MeSH & PubMed Central & $\begin{array}{l}\text { NLM } \\
\text { Catalog }\end{array}$ & BookShelf & \\
\hline 1 & Endoscopic third ventriculostomy & 3301 & 1 & 2144 & 6 & 54 & 5506 \\
\hline 2 & $\begin{array}{l}\text { Endoscopic anatomy of third } \\
\text { ventricle }\end{array}$ & 639 & 0 & 827 & 3 & 10 & 1479 \\
\hline 3 & $\begin{array}{ll}\begin{array}{l}\text { Endoscopic } \\
\text { challenges }\end{array} & \text { ventriculostomy } \\
\end{array}$ & 18 & 0 & 175 & 0 & 3 & 196 \\
\hline 4 & Hydrocephalus etiology & 17403 & 0 & 12912 & 39 & 276 & 30630 \\
\hline 5 & $\begin{array}{l}\text { Patient age impact on third } \\
\text { ventriculostomy }\end{array}$ & 19 & 0 & 398 & 0 & 3 & 420 \\
\hline 6 & Third ventriculostomy complications & 891 & 0 & 904 & 0 & 8 & 1803 \\
\hline 7 & Ideal hydrocephalus patient selection & 2 & 0 & 590 & 0 & 11 & 603 \\
\hline 8 & ETV treatment modalities & 9 & 0 & 138 & 0 & 0 & 147 \\
\hline
\end{tabular}

\subsection{Data Inspection:}

Our data inspection approach was directly based upon our study objectives. From each included study focusing third ventriculostomy detailed information was extracted which includes, author of the study, publication year, number of cases enrolled, gender ratio, age of patients, surgical complications, neurogenic disorder, relevant outcome and limitations of the each included study as well.

\subsection{Data validity and Quality Enhancement:}

Retrieved useful data validity was ensured by two independent authors following specific data cross checking approach. First author affiliation was considered as the origin of the study for each includedresearch. In case of more than one affiliations of the first author, primary affiliationwas preferred. For each included study quality score was calculated by comparing relative outcome scores versus reported complications.

\subsection{Studies Processed:}

Only 11 studies were further processed for meta-analysis to determine exact role of patient age following endoscopic third ventriculostomy as shown in Table.1

\subsection{Statistical Analysis:}

Complete demographic details of each included study and its outcomes were tabulated and analyzed by using SAS and multiple tools of Microsoft office Version 2010.

\section{RESULT}

From total 11 included studies specifically focusing hydrocephaly treatment via endoscopic third ventriculostomy, 757 patients with equal 1:1 male and female gender ratio and 125 cases of unknown gender were considered. Current study highlighting efficacy of Endoscopic third ventriculostomy at the rate of $77 \%$ effective treating obstructive hydrocephalus (Table.6).

\subsection{Meta-Analysis:}

Meta-Analysis was performed by using SAS University Edition, from each included study focusing third ventriculostomy detailed information was extracted which includes, author of the study, publication year, number of cases 
Dipak Chaulagain et.al. Comparative role of hydrocephalus etiology and patient age following third ventriculostomy.

enrolled, gender ratio, age of patients, and relevant outcome. (Table. 3). surgical complications, neurogenic disorder

Table.3. Detailed Meta-Analysis focusing Endoscopic third ventriculostomy in hydrocephalus patients.

\begin{tabular}{|c|c|c|c|c|c|c|c|c|}
\hline Study Author & $\begin{array}{l}\text { Publication } \\
\text { year }\end{array}$ & $\begin{array}{l}\begin{array}{l}\text { Neurogenic } \\
\text { disorder }\end{array} \\
\end{array}$ & $\begin{array}{l}\text { Cases } \\
\text { Enrolled } \\
\end{array}$ & Female & Male & Other & $\begin{array}{l}\text { Surgical } \\
\text { technique }\end{array}$ & Outcomes \\
\hline Vulcu, S et al & 2015 & $\begin{array}{l}\text { Obstructive } \\
\text { hydrocephaly }\end{array}$ & 113 & 55 & 58 & & ETV & $\begin{array}{l}82-78 \% \text { success rate } \\
\text { from short to long } \\
\text { follow up }\end{array}$ \\
\hline Rahman MM et al & 2018 & $\begin{array}{l}\text { Obstructive } \\
\text { hydrocephaly }\end{array}$ & 60 & 0 & 0 & 60 & $\begin{array}{l}\text { ETV\& } \\
\text { VPS }\end{array}$ & $\begin{array}{l}\text { Clear impact of age } \\
\text { following } \\
\text { Success Rate. }\end{array}$ \\
\hline Sodhiya P et al & 2019 & hydrocephaly & 30 & 15 & 15 & 0 & ETV & $\begin{array}{l}\text { ETV is } 100 \% \\
\text { successful in patients } \\
\text { with aqueduct } \\
\text { stenosis }\end{array}$ \\
\hline $\begin{array}{l}\text { Udayakumaran, } \mathrm{S} \\
\text { et al }\end{array}$ & 2019 & $\begin{array}{l}\text { Obstructive } \\
\text { hydrocephaly }\end{array}$ & 65 & 0 & 0 & 65 & ETV & $\begin{array}{l}\text { MRI is } 96 \% \text { sensitive } \\
\text { predictor of ETV }\end{array}$ \\
\hline Stachura, $\mathrm{K}$ et al & 2014 & $\begin{array}{l}\text { Obstructive } \\
\text { hydrocephaly }\end{array}$ & 96 & 41 & 55 & 0 & ETV & $\begin{array}{l}\text { ETV is successful in } \\
\text { patients with aqueduct } \\
\text { stenosis }\end{array}$ \\
\hline He, Z. et al & 2015 & hydrocephaly & 17 & 8 & 9 & 0 & ETV & $\begin{array}{l}\text { ETV is safe and best } \\
\text { for Infantile } \\
\text { hydrocephaly. }\end{array}$ \\
\hline Labidi, M et al & 2015 & hydrocephaly & 168 & 86 & 82 & 0 & ETV & ETV is $70 \%$ effective. \\
\hline Rei, J., et al & 2017 & myelomeningocele & 18 & 6 & 12 & 0 & ETV & $\begin{array}{l}\text { ETV is effective in } \\
\text { older patients }\end{array}$ \\
\hline Haque, M., et al & 2017 & $\begin{array}{l}\text { Obstructive } \\
\text { hydrocephaly }\end{array}$ & 17 & 9 & 8 & 0 & ETV & $\begin{array}{l}\text { ETV is successful in } \\
\text { patients with aqueduct } \\
\text { stenosis }\end{array}$ \\
\hline Ojo OA., et al & 2015 & hydrocephaly & 34 & 17 & 17 & 0 & ETV & $\begin{array}{l}\text { Patient selection and } \\
\text { experience of } \\
\text { neurosurgeon play } \\
\text { important role in ETV } \\
\text { Success. }\end{array}$ \\
\hline Talamonti, G. et al & 2019 & $\begin{array}{l}\text { Obstructive } \\
\text { hydrocephaly }\end{array}$ & 139 & 78 & 61 & 0 & $\begin{array}{l}\text { ETV\& } \\
\text { VPS }\end{array}$ & $\begin{array}{l}\text { ETV is now the } \\
\text { procedure of choice } \\
\text { for most patients with } \\
\text { VPS malfunctions. }\end{array}$ \\
\hline
\end{tabular}

Other: unknown gender.

\subsection{Clinical Association of Age following ETV:}

Our review divided patients into age groups in age range $\leq 6$ month-1 year, Age range $>1$ - 15 year, Age range $>16-30$ year and Age range $>30$ year to draw an updated success rate of ETV parallel to different age groups. As Table.4 shows highest number of cases were reported in Age range $>16-30$ year. However, $15 \%$ cases were in age range of $\leq 6$ month- 1 year and $26 \%$ cases were reported in age range of greater than
30 year. Relative age associated ETV success rate was calculated by dividing number of patients in specific age group on total number of complications observed following post endoscopic third ventriculostomy. In age group Age range $\leq$ 6 month-1 year only 26 cases out of 112 shown complications, 36 complication cases in age group Age group $>1$ - 15 year, 66 cases in age group $>16-30$ year out of 290 total cases were observed with post ETV complications.

Table. 4. Age wise association of post ETV complications.

\begin{tabular}{|l|l|l|l|l|}
\hline Age range $\leq$ 6 month-1 year & Age range $>\mathbf{1}-\mathbf{1 5}$ year & Age range $>$ 16-30 year & Age range $>$ 30 year & Mean age (Y) \\
\hline 4 & 0 & 21 & 88 & 35 \\
\hline 0 & 51 & 1 & 8 & 17.8 \\
\hline 5 & 14 & 5 & 6 & 16.5 \\
\hline 23 & 18 & 24 & 0 & 6 \\
\hline 0 & 0 & 0 & 96 & 47 \\
\hline 17 & 0 & 0 & 0 & 0.4 \\
\hline 0 & 12 & 156 & 0 & 40 \\
\hline 12 & 6 & 0 & 0 & 2.75 \\
\hline 17 & 0 & 0 & 0 & 0.45 \\
\hline 34 & 0 & 0 & 0 & 2.5 \\
\hline 0 & 0 & 83 & 0 & 29.4 \\
\hline
\end{tabular}


Dipak Chaulagain et.al. Comparative role of hydrocephalus etiology and patient age following third ventriculostomy.

\subsection{Etiological Factors:}

Table.5. Etiological factors involved in pre-ETV obstructive hydrocephalus.

\begin{tabular}{|c|c|c|c|c|}
\hline \multicolumn{5}{|c|}{ Disease etiology } \\
\hline $\begin{array}{l}\text { Benign } \\
\text { aqueductal } \\
\text { stenosis }\end{array}$ & Tumor & Infection/hemorrhage & Cyst & other \\
\hline 40 & 35 & 15 & 13 & 10 \\
\hline 0 & 0 & 0 & 0 & 60 \\
\hline 8 & 11 & 0 & 2 & 9 \\
\hline 0 & 0 & 13 & 0 & 52 \\
\hline 24 & 63 & 0 & 0 & 9 \\
\hline 0 & 0 & 2 & 0 & 15 \\
\hline 59 & 62 & 20 & 5 & 22 \\
\hline 0 & 0 & 0 & 0 & 18 \\
\hline 0 & 0 & 0 & 0 & 17 \\
\hline 0 & 0 & 5 & 0 & 29 \\
\hline 23 & 12 & 67 & 3 & 34 \\
\hline
\end{tabular}

Table. 6. Post-ETV complication score.

\begin{tabular}{|l|l|l|}
\hline Cases Enrolled & Complications cases & Net Score \\
\hline 113 & 10 & 1.32 \\
\hline 60 & 19 & 2.51 \\
\hline 30 & 3 & 0.40 \\
\hline 65 & 13 & 1.72 \\
\hline 96 & 22 & 2.91 \\
\hline 17 & 1 & 0.13 \\
\hline 168 & 42 & 5.55 \\
\hline 18 & 10 & 1.32 \\
\hline 17 & 3 & 0.40 \\
\hline 34 & 2 & 0.26 \\
\hline 139 & 49 & 6.47 \\
\hline 757 & 174 & 23.0 \\
\hline
\end{tabular}

On basis of etiological concerns about $36.32 \%$ cases hydrocephalous cases were linked with encephalitis, underweight birth and nonspecific etiology. However, 24 $\%$ cases of hydrocephalus were led by group of tumors including, Ependymoma, Medulloblastoma, Meningioma, Cerebella pontine angle Tumors and Pineal gland carcinomas as well. 154 (20\%) cases of obstructive hydrocephalus were associated with aqueduct stenosis, $16 \%$ cases reporting hemorrhage and only 23 cyst cases (Table.5).

Average complications rate reported from all age groups was approximately 23 \%. (Table.4).

\section{DISCUSSION}

On the behalf of recent six-year available literature, our review reported $77 \%$ efficacy of endoscopic third ventriculostomy following obstructive hydrocephaly, Intriguingly, even a single study did not contradict our hypothesis regarding effectiveness of endoscopic third ventriculostomy. As this is first approach considering impact of etiology and age following treatment approaches towards obstructive hydrocephalus. However, study conducted by Vulcu, S et al in 2015 reported 78-82 \% efficacy of endoscopic third ventriculostomy, which purely matches with our outcomes. Similarly, study led by Labidi, $\mathrm{M}$ et al same year focusing 168 subjects reported 70\% efficacy and 30\% complications were noted following ETV as a treatment of choice in obstructive hydrocephalus patients. Whereas, we report $23 \%$ complications a slight less then author reported. (Graph.1). Similarly, surgeon expertise in patient selection is considered gold standard for successful ETV. Ojo OA., et al acknowledged in his study during 2015 a significant role of patient selection following ETV.

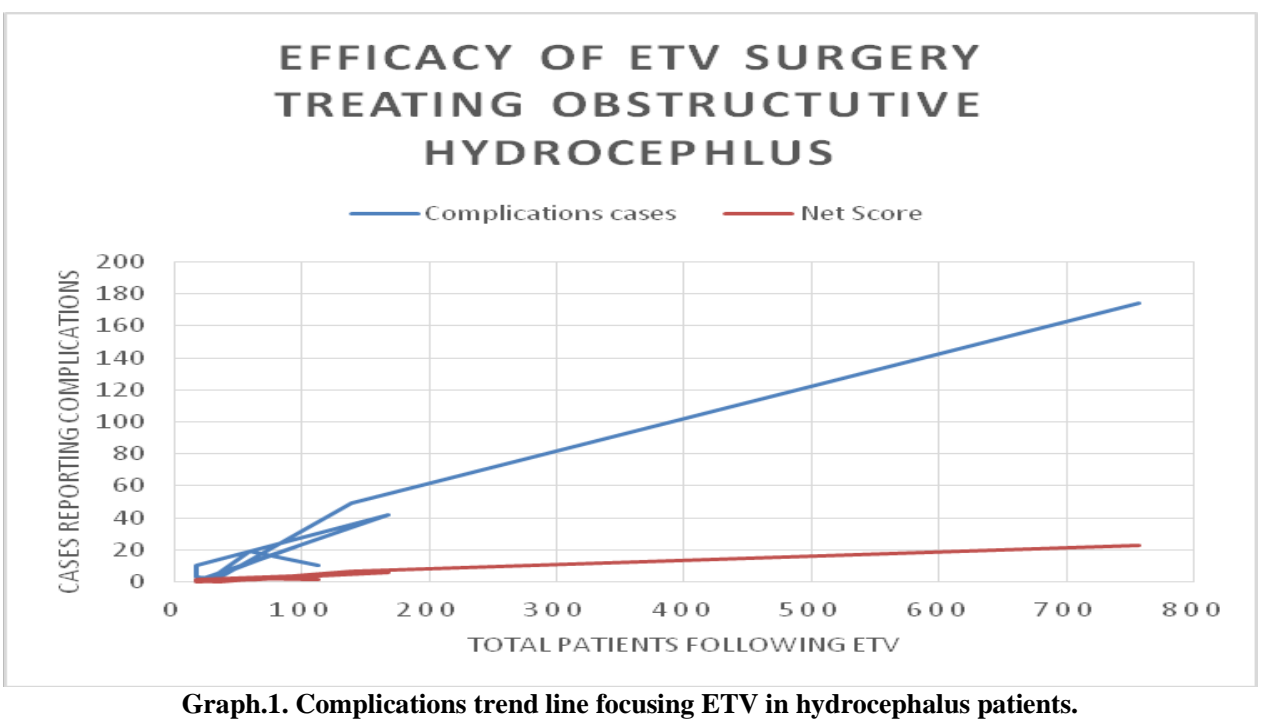


Dipak Chaulagain et.al. Comparative role of hydrocephalus etiology and patient age following third ventriculostomy.

Obstructive hydrocephalus cases with aqueductal stenosis symptoms are considered ideal choice following endoscopic third ventriculostomy.

\section{Success and Limitations:}

Current study is first approach analyzing ETV impact while treating hydrocephalus disorder among distinct age groups and its relative effectiveness. We are first describing ideal patient selection criteria and its relative clinical importance following ETV surgery success rate treating obstructive hydrocephalous.

\section{CONCLUSION AND RECOMMENDATIONS}

Endoscopic third ventriculostomy (ETV) is a safe and effective (77\%) treatment option for the treatment of obstructive hydrocephalus among all age groups. However, specifically highest efficacy was noted among patients of 15-30year age group. Understanding disease etiology and patient selection criteria both are considered potential components following successful endoscopic third ventriculostomy. The major challenge faced during research process was lack of universal age criteria for each included study. We highly recommend further research following a universal age criteria and reporting results in distinct age category to standardize ETV treating hydrocephaly efficiently.

Abbreviations: ETV $=$ Endoscopic third ventriculostomy, $\mathbf{C S F}=$ Cerebrospinal fluid, VPS $=$ Ventriculoperitoneal shunt surgery, MRI= magnetic resonance imaging,

\section{Conflict of Interest: None}

\section{REFERENCES}

1. Yadav YR, Parihar V, Pande S, Namdev H, Agarwal M. Endoscopic third ventriculostomy J Neurosci Rural Pract. (20120;3(2):163-73.

2. Dusick JR, McArthur DL, Bergsneider M. Success and complication rates of endoscopic third ventriculostomy for adults hydrocephalus: a series of 108 patients. Surg Neurol. (2008);69:5-15.

3. Jernigan SC, Berry JG, Graham DA, Goumnerova L. The comparative effectiveness of ventricular shunt placement versus endoscopic third ventriculostomy for initial treatment of hydrocephalus in infants. J NeurosurgPediatr. (2014);13:295-300.

4. Santamarta D, Martin-Vallejo J, DíazAlvarez A, Maillo A. Changes in ventricular size after endoscopic third ventriculostomy. Acta Neurochir (Wien). 2008;150:119-27.

5. Schwartz TH, Yoon SS, Cutruzzola FW, Goodman RR. Third ventriculostomy: postoperative ventricular size and outcome. Minim Invasive Neurosurg. 1996;39:122-9.

6. Grunert P, Charalampaki P, Hopf N, Filippi R. The role of third ventriculostomy in the management of obstructive hydrocephalus. Minim Invasive Neurosurg2003;46:16-21.

7. Buxton N, Turner B, Ramli N, Vloeberghs $M$. Changes in third ventricular size with neuroendoscopic third ventriculostomy: A blinded study. J Neurol Neurosurg Psychiatry 2002;72:385-7.

8. Feng H, Huang G, Liao X, Fu K, Tan H, Pu $\mathrm{H}$, et al. Endoscopic third ventriculostomy in the management of obstructive hydrocephalus: An outcome analysis. J Neurosurg2004;100:626-33.

9. Drake JM, Iantosca MR. Cerebrospinal fluid shunting andmanagement of pediatric hydrocephalus. In: Schmidek HH,Roberts DW, editors. Schmidek\& Sweet Operative NeurosurgicalTechniques: Indications, Methods, and Results. 5th ed.Philadelphia: Saunders Elsevier; 2006. p. 488-99.

10. Lindsay KW, Bone I. Neurology, and Neurosurgery Illustrated.4th ed. London: Churchill Livingstone; 2004. p. 370-3.

11. Di Rocco C, Massimi L, Tamburrini G. Shunts vs. endoscopic third ventriculostomy in infants: Are there different types and/or rates of complications? A review. Childs Nerv Syst 2006;22:1573-89.

12. El-Ghandour NM. Endoscopic third ventriculostomy versusventriculo-peritoneal shunts in the treatment of obstructive hydrocephalus due to posterior fossa tumors in the children. Childs Nerv Syst 2010;381:1263-5.

13. Teo C, Mobbs R. Neuroendoscopy. In: Rengachary SS,Ellenbogen RG, editors. Principles of Neurosurgery. 2nd ed.London: Elsevier Mosby; 2005. p. 146-7. 
Dipak Chaulagain et.al. Comparative role of hydrocephalus etiology and patient age following third ventriculostomy.

14. Buxton N, Ho KJ, Macarthur D, Vloeberghs M, Punt J,Robertson I. Neuroendoscopic third ventriculostomy for hydrocephalus in adults: Report of a single unit's experience with 63 cases. Surg Neurol 2001;55:74-8.

15. Dusick JR, McArthur DL, Bergsneider M. Success and complication rates of endoscopic third ventriculostomy for adult hydrocephalus: A series of 108 patients. Surgical Neurology. 2008 Jan;69(1):5-15

16. Sankey EW, Goodwin CR, Jusué-Torres I, Elder BD, Hoffberger J, Lu J, et al. Lower rates of symptom recurrence and surgical revision after primary compared with secondary endoscopic third ventriculostomy for obstructive hydrocephalus secondary to aqueductalstenosis in adults. Journal of Neurosurgery. 2016 May; 124(5):1413-1420

17. Buxton N, Ho KJ, Macarthur D, Vloeberghs M, Punt J, Robertson I. Neuroendoscopic third ventriculostomy for hydrocephalus in adults: Report of a single unit's experience with 63 cases. Surgical Neurology. 2001;55(2):74-78

18. Morgenstern PF, Souweidane MM. Pineal Region Tumors: Simultaneous Endoscopic Third Ventriculostomy and Tumor Biopsy. World Neurosurgery. 2013;79(2):S18.e9S18.e13

19. Wellons JC, Shane Tubbs R, Banks JT, Grabb B, Blount JP, Jerry Oakes W, et al. Long-term control of hydrocephalus via endoscopic third ventriculostomy in children with tectalplate gliomas. Neurosurgery. 2002;51(1):63-68.

20. Li KW, Roonprapunt C, Lawson HC, Rick Abbott I, Wisoff J, Epstein F, et al. Endoscopic third ventriculostomy for hydrocephalus associated with tectal gliomas. Neurosurgical Focus. 2005;18(6):1-4.

21. Cinalli G, Sainte-Rose C, Chumas P, Zerah M, Brunelle F, Lot G, et al. Failure ofthird ventriculostomy in the treatment of aqueductal stenosis in children. Journal of Neurosurgery. 1999 Mar;90(3):448-454

22. Kulkarni AV, Riva-Cambrin J, Holubkov R, Browd SR, Cochrane DD, Drake JM, et al. Endoscopic third ventriculostomy in children: Prospective, multicenter results from the hydrocephalus clinical research network. Journal of Neurosurgery. Pediatrics. 2016 Oct;18(4):423-429.
23. Schroeder HWS. A new multipurpose ventriculoscope. Neurosurgery. 2008 Feb;62(2):489-491 discussion 491-2.

24. Schroeder HWS, Warzok RW, Assaf JA, Gaab MR. Fatal subarachnoid hemorrhage after endoscopic third ventriculostomy. Neurosurgical Focus. 1999; 6(4):E6

25. Weil AG, Fallah A, Chamiraju P, Ragheb J, Bhatia S. Endoscopic third ventriculostomy and choroid plexus cauterization with a rigid neuroendoscope in infants with hydrocephalus. Journal of Neurosurgery. Pediatrics. 2015 Oct 30:1-11

26. Kulkarni AV, Drake JM, Kestle JRW, Mallucci CL, Sgouros S, Constantini S, et al. Predicting who will benefit from endoscopic third ventriculostomy compared with shunt insertion in childhood hydrocephalus using the ETV success score. Journal of Neurosurgery. Pediatrics. 2010 Oct;6(4):310-315

27. Romero L, Ros B, Ibáñez G, Ríus F, González L, Arráez M. Endoscopic third ventriculostomy:Can we predict success during surgery? Neurosurgical Review. 2014Jan;37(1):89-97.

28. Wagner W, Koch D. Mechanisms of failure after endoscopic third ventriculostomy in young infants. Journal of Neurosurgery. 2005 Jul;103(Suppl 1):43-49.

29. Vulcu, S., Eickele, L., Cinalli, G., Wagner, W., \&Oertel, J. (2015). Long-term results of endoscopic third ventriculostomy: an outcome analysis. Journal of Neurosurgery, 123(6), 14561462.doi:10.3171/2014.11.jns14414.

30. Rahman MM, Salam MA,Uddin K, Rahman MM, Islam MR, Haque MA,et al. Early surgical outcome of endoscopic third ventriculostomy in the management of obstructive hydrocephalus: A randomized control trial. Asian JNeurosurg 2018; 13:1001-4.

31. Sodhiya P, Sheikh ZA, Sharma M, Morey M. Endoscopic third ventriculostomy for hydrocephalus: a study of thirty cases. Int Surg J 2019;6:1120-6.

32. Udayakumaran, S., \& Joseph, T. (2019). Can We Predict Early Endoscopic Third Ventriculostomy Failure? The Role of Ultra-Early Postoperative Magnetic Resonance Imaging in Predicting Early Endoscopic Third Ventriculostomy Failure. World Neurosurgery: $X, \quad 2$, 100013.doi:10.1016/j.wnsx.2019.100013. 
Dipak Chaulagain et.al. Comparative role of hydrocephalus etiology and patient age following third ventriculostomy.

33. Stachura, K., Grzywna, E., Kwinta, B. M., \&Moskała, M. M. (2014). Endoscopic third ventriculostomy - effectiveness of the procedure for obstructive hydrocephalus with different etiology in adults. Videosurgery and Other Miniinvasive Techniques, $\quad 4, \quad 586-$ 595. doi:10.5114/wiitm.2014.46076.

34. He, Z., An, C., Zhang, X., He, X., \& Li, Q. (2015). The efficacy analysis of endoscopic third ventriculostomy in infantile hydrocephalus. Journal of Korean Neurosurgical Society, 57(2), 119-122. doi:10.3340/jkns.2015.57.2.119.

35. Labidi, M., Lavoie, P., Lapointe, G., Obaid, S., Weil, A. G., Bojanowski, M. W., \& Turmel, A. (2015). Predicting success of endoscopic third ventriculostomy: validation of the ETV Success Score in a mixed population of adult and pediatric patients. Journal of Neurosurgery, 123(6), 1447-1455.doi:10.3171/2014.12.jns141240

36. Rei, J., Pereira, J., Reis, C., Salvador, S., \&Vaz, R. (2017). Endoscopic Third Ventriculostomy for the Treatment of Hydrocephalus in a Pediatric Population with Myelomeningocele. World Neurosurgery, 105, 163-169. doi:10.1016/j.wneu.2017.05.107
37. Haque, M., Kawsar, K., Sarker, M., Haque, A. F. M., \& Chowdhury, F. (2017). Result of Endoscopic Third Ventriculostomy for Hydrocephalus Caused by Cerebral Aqueductal Stenosis in Infant Patients. Indian Journal of Neurosurgery, 06(03), 189-197. doi:10.1055/s-0037-1607053

38. Ojo OA, Bankole OB, Kanu OO, Okubadejo NU. Efficacy of endoscopic third ventriculostomy in the management of hydrocephalus in children under 2 years of age: Experience from a tertiary institution in Nigeria. Niger J Clin Pract2015;18:318-22.

39. Talamonti, G., Nichelatti, M., Picano, M., Marcati, E., D’Aliberti, G., \&Cenzato, M. (2019). Endoscopic third ventriculostomy for ventriculoperitoneal shunt malfunction: does shunt duration play a role? World Neurosurgery.doi:10.1016/j.wneu.2019.03.2 68.

How to cite this article: Dipak Chaulagain, Volodymyr Smolanka, Andriy Smolanka et.al. Clinical impact of the patient age following endoscopic third ventriculostomy: a review. Int J Health Sci Res. 2021; 11(12):188-196. DOI: https://doi.org/10.52403/ijhsr.20211225 